\title{
Games: contemporâneo, subjetividade e utopia
}

\section{Games: contemporary subjectivity and utopia}

\begin{abstract}
Resumo: Em meio a este grande turbilhão tecnológico no qual vivemos hoje, um grande ambiente de propagação de tecnologias da informação e comunicação, presenciamos as práticas sociais e culturais transformarem-se de maneira significativa. Vários estudos têm sido realizados nos últimos anos a respeito da tecnologia e as implicações com o sujeito histórico, mas poucos a respeito de um território no mínimo novo e instigante, os vídeos games. Assim este texto busca compor uma cartografia a respeito dos games como intercessores da Psicologia, desdobrando sentidos e novas formas inventivas de existência, para dessa maneira entendermos essas produções tecnológicas como uma potente ferramenta de vida e criação, em um território múltiplo e paradoxal.
\end{abstract}

Palavras-chave: Cartografia. Games. Contemporâneo. Utopia.

Abstract: In the midst of this great technological whirlwind in which we live today, a great environment for the spread of information and communication technologies, we see the social and cultural practices becoming significantly. Several studies have been made in recent years about the technology and its implications with the historical subject, but few regarding a territory at least new and thought-provoking, the video games. Thus this text search compose a cartography of games as intercessors of Psychology, unfolding senses and inventive new ways of existence in this way we understand these technological productions as a powerful tool of life and creation in one territory and paradoxical. Keywords: Cartography. Games. Contemporary. Utopia.

DAMIAN, Davi S. Menezes. Games: contemporâneo, subjetividade e utopia. Informática na Educação: teoria e prática, Porto Alegre, v. 16, n. 1, p. 173-190, jan./jun. 2013.

\section{Davi Severo Menezes Damian}

FADERGS

\section{0 que podem os games?}

0 $s$ games $^{1}$ estão se revelando uma potente ferramenta, adentrando arte e educação. Mesmo assim, por vezes são vistos como uma produção underground ${ }^{2}$ ou feita apenas para entreter, tendo como público alvo uma massa infantil ou infantilizada, não fugindo também de sua fabricação para venda e ganho monetário como qualquer outra mercadoria. Neste último caso, várias pesquisas feitas com jovens na década de 80 como na década de 90 tinham como objetivo, um tanto tendencioso, de "provar" que jogar causaria algum tipo de dano, tanto físico (danos aos globos oculares, causando miopia ou outra lesão) ou que games violentos deixariam os jogadores também com

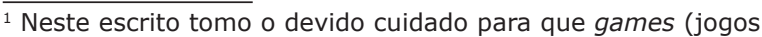
digitais) não sejam confundidos com vídeo games, conhecidos no senso comum como consoles, os aparelhos onde são executados os games.

2 Eles podem ser vistos como underground, dando forma a pequenos nichos especializados e fechados que se voltam aos games (games específicos ou não) ou apenas como mais um produto da indústria cultural, voltado apenas para o entretenimento dos seus consumidores.
} 
atitudes agressivas, como também problemas de aprendizado a nível escolar. Mesmo não tendo dados consistentes sobre estes três aspectos, formou-se um estigma quando se fala em games ou em títulos específicos de gênero de Luta ou Corrida e Ação, o game de luta Mortal Kombat chegou a ser proibido em certos países pelo nível de violência na década de 90 , hoje ainda temos estes tipos de estudos mesmo assim, tais pesquisas remetem a um conteúdo tendencioso, favorecedores de ordem discursiva no mínimo hipócrita, em vista de uma tentativa de uso de um saber científico para legitimar dados e resultados, neste caso, sem propiciar uma abertura de pensamento sobre as produções culturais vistas hoje, não apenas em games. Uma vez que a "leitura" que se faz de um game dependeria do contexto social, cultural, histórico e as relações de poder, mas o que vemos é a simplista forma do "certo" e "errado" limitando seu entendimento.

Games devem ser concebidos como uma prática social um território que surge com uma exigência de pensamento, uma convocação à criação! Inscrevem-se na cultura e são inscritos por ela, fundando outros modos de afetação e problematização, outra forma de compartilhar uma experiência, possibilitar uma possibilidade. Um exemplo de uma ética criada com os games e a partir dos mesmos:

The proliferation of games for serious purposes in recent years has been nothing short of astounding. Although using games for training and marketing is a phenomenon with a considerable history the present surge of interest marks an unmistakable mainstreaming of the concept that games can be efficient means of persuasion, branding, education, and communication. A telling example is the recent initiative of the Danish agency in charge of recycling of bottles and cans (Dansk Retursystem A/S). Wanting to increase kno- wledge and compliance the agency launched two web-based games (SMITH, 2003). ${ }^{3}$

Vemos a implicação de uma política de meio ambiente de reciclagem de garrafas tendo um game cujo conteúdo é ensinar ao jogador como reciclar e que materiais estão disponíveis para tal. São dois jogos disponibilizados por uma empresa de reciclagem, um deles coloca o jogador na posição de motorista e que deve coletar itens descartados em uma cidade. Percebemos tais produções como frutos de agenciamentos entre arte e tecnologia criando algo novo (ou possibilitando uma crítica a algo estabelecido), propiciando também outras maneiras de observarmos a relação do ser humano com sua sociedade, suas angústias, afectos e a relação consigo mesmo. Mas também notamos como esses jogos são elaborados com o atravessamento de valores culturais e ideológicos de seus financiadores/ produtores e o jogador por fim, experimenta tais valores e ideologias.

Cativar (ou castigar) com imagens e sons, treinar, preparar, ou então, mostrar outros lados, viajar pelo mundo, visitar lugares, e/ou (re)visitar momentos históricos muitas vezes ignorados por uma ordem discursiva vigente, games podem ser uma ortopedia da subjetividade ou também focos de resistência contra repetição exigindo a diferença. Mostram-nos o ser em movimento, e dizer que há muito tempo esta forma de arte foi marginalizada por discursos de saber, mas algumas fissuras foram criadas por pensadores resistentes a formas de controle neste tipo de processo artístico, tais pensadores (como designers desta forma de arte) nos mostraram que como pinturas ou esculturas, os games vão além das imagens

\footnotetext{
3 Disponível em: http://game-research.com/index.php/book-reviews/book-review-persuasive-games-the-expressive-power-of-videogames/ Acesso em: 10 mar. 2011.
} 
e das palavras, com a invenção de velhas ou novas possibilidades de vida.

\section{Game como cópia: a reprodução e a representação do mundo}

Nos últimos anos vemos o desenvolvimento gráfico de inúmeros jogos que reproduzem efeitos de realidade, com trabalho de texturas e geometria que beiram a "perfeição", como se realmente fosse visto na tela um carro de corrida real, uma árvore balançando com o vento e o brilho dos olhos de um cachorro devido tamanha rapidez com os quais os games e as plataformas gráficas têm possibilitado. Presenciamos um trabalho e atenção aos mínimos detalhes para que os games sejam os mais próximos da realidade ou mais próximos daquilo que querem reproduzir, seja uma corrida automobilística ou uma partida de futebol com sombra, luz e som possuindo uma aparência tão próxima a uma competição vista ao vivo pela televisão. Algo tão espantoso que muitos games estão sendo desenvolvidos para treinamento reproduzindo situações reais, ou produtoras que contratam pessoal especializado para que os games sejam produzidos de maneira fiel ao contexto proposto, Tiro, Corrida, Luta etc.

Tomamos como exemplo o game Medal of Honor (1999), este tem como fundo a Segunda Guerra Mundial, não por acaso, os produtores deste jogo foram os mesmos do filme "O resgate do soldado Ryan" (1998), entre eles Steven Spielberg, então, Medal of Honor ( $\mathrm{MoH})$ levando grandes nomes do cinema para outro território, puxou a produção de games para outro patamar, o apoio direto de estúdios cinematográficos, se bem que isso já ocorrera antes como games da franquia Star Wars, mas neste momento (1999) um boom desencadeou fabricações em várias janelas da arte. Com o lançamento de "O Resgate do Soldado Ryan", foram lançados dezenas de filmes baseados neste conflito armado, mas com os games a onda de choque deste boom foi ainda mais distante, a franquia $\mathrm{MoH}$ tem mais de dez seqüências, outras produtoras também lançaram games com a mesma temática, e uma possível conseqüência disso foi uma saturação do mercado tanto de games como do cinema pela exploração abusiva desta guerra. Mas com pouco interesse em oferecer uma tentativa de questionamento com relação a um dos mais sangrentos acontecimentos históricos. Na Alemanha este game gerou certa polêmica, pois é claro, tornava novamente presente a lembrança deste momento sombrio, o que quase ocasionou a proibição da venda no game no mercado alemão. Percebe-se a capacidade do game produzir experiências e efetuar complexas relações no mundo da política e das artes.

Mas não tentemos efetuar uma hierarquização destas produções, um platonismo, um mundo de Idéias para que se entenda os games como um mundo ideal, da matemática e essências, ou ainda considerar que são o reflexo de algo externo (mundo real) e/ou interno (fantasias da subjetividade de seus criadores), tendo como única relação a jogador-produtor da matéria produto, neste caso um game em si, criado 'do nada', tendo um entendimento deveras limitado como se os games fossem 'um mundo inferior' e os jogadores seres que optaram por uma ilusão vista em uma caixa de imagens e que devemos ter um mapa, uma forma de 'descobri-lo', de vermos suas verdades, vê-lo como cópia da realidade externa ao mesmo (modelo), dando contornos e limites, esquadrinhando cada passo e cada frame, ou mesmo produzir uma classificação artística dos 
games relativa a sua capacidade de representação, ilusão (qualidade dos gráficos, jogabilidade, etc.). Tentemos sim explorar e dialogar entre conceitos, não comparar games com uma possível realidade, mas sim associá-los aos discursos e enunciados nos quais se inscrevem e são inscritos, tomemos rapidamente para isso um comentário de Gilles Deleuze sobre o simulacro, para além de enunciados platônicos:

O simulacro implica grandes dimensões, profundidades e distâncias que o observador não pode dominar. É porque não as domina que ele experimenta uma impressão de semelhança. O simulacro inclui em si o ponto de vista diferencial; o observador faz parte do próprio simulacro, que se transforma e se deforma com seu ponto de vista (DELEUZE, 1969 , p. 264).

Com o avanço da tecnologia, presenciamos a tentativa da cópia aproximar-se a imagem do modelo, mas mesmo com essa aproximação, esse movimento escancara a singularidade. Por vezes a própria "cópia" se torna o novo modelo, e então tal primazia de uma hierarquia platônica entre mundos torna-se insuficiente diante de tal movimento tecnológico que produzem tais cópias com as mesmas imperfeições que a original ${ }^{4}$ a ponto de tornarem-se 'perfeitas' e serem confundidas umas com as outras, como é o caso de games de futebol ${ }^{5}$ que transformaram as transmissões das partidas e estão transformando suas regras para tornar o esporte mais próximo do espetáculo ofertado pelo game:

\footnotetext{
${ }^{4}$ Como no filme Matrix de 1999. Para a Matrix foi necessária a introdução de imperfeições na simulação, pois com a inserção de um mundo pleno, sem faltas, a Matrix perdeu vários 'usuários', pois cometiam suicídio devido a um mundo onde todos os desejos se realizavam, e sem usuários, a Matrix não sobreviveria, surgindo então a demanda por um 'mundo imperfeito', um "real da Matrix".

${ }^{5}$ Exemplos como Fifa Soccer 2010 ou PES 2010.
}

Os simulacros ultrapassam a dualidade das proposições entre designação de coisas e expressão de sentido, acolhendo aos efeitos, aos sentidos, as ações e as expressões, como se mais que coisas fossem. Colocamo-nos, então, para além da retificação do ser em forma ou substância, posto que estes se dissolvem nos fluxos: a própria expressão já é. O problema da ausência de designação, de referente no mundo das coisas, representações ou modelos inteligíveis, não é mais uma barreira ao simulacro. Importa sim seus efeitos, suas expressões: sua potencia poética é sua força poiética e vice-versa. (FONSECA et al., 2010, p. 182).

Podem muito bem tornarem-se perfeitas cruzando rapidamente um anel de Moebius tecnológico e afectivo sempre mantendo sua singularidade, sua afronta a um modelo (os campeonatos de futebol podem ser mais dinâmicos e com passes perfeitos?), a ponto que não seria mais possível identificar suas diferenças pondo em questão as noções de copia e modelo, assim, no novo game Medal of $\mathrm{Honor}^{6}$ (2010), foram chamados veteranos do conflito Afeganistão/Iraque para que o game fosse 0 mais real e próximo a um conflito armado possível, não só este, os produtores do game "Fórmula 1: 2010" convidaram pilotos das escuderias para opinarem sobre o desenvolvimento do jogo. Vemos a semelhança como potência para a diferença, para a multiplicidade, exprimir o funcionamento do simulacro, pois mesmo pensando que presenciamos o mesmo, o que vemos trata-se de uma diferença.

Percebemos este movimento em que há toda uma diversidade de games que se utilizam de um Platonismo, de uma lógica modelo-cópia para produzir games cada vez mais próximos do real. Assim, há um momento que isso

\footnotetext{
${ }^{6}$ Agora este novo game tem como conteúdo o conflito no Afeganistão/Iraque, não mais a Segunda Guerra Mundial.
} 
produz uma hiper-realidade e o game passa paradoxalmente de cópia para modelo, e passa a regrar as formas do chamado "mundo real", no sucinto escrito "Lyotard, Baudrillard, Language Games and Simulacra, Oh My?!" (MACKEY, 2007), temos uma fala do pensador Jean Baudrillard a qual nos diz que vivemos em um mundo de sentimentos e sensações simulados, imagens de produção em massa, shoppings e programas de TV são alguns exemplos, cita ele também, a Guerra do Golfo do inicio da década de noventa, imagens com 'visão noturna' sendo transmitidas ao vivo pela TV, com semeIhança espetacular a games. Mas dessa forma também, games que se aproximam de uma situação real são produzidos com um foco específico para serem usados no tratamento de soldados com estresse pós-traumático. ${ }^{8}$

Uma terapia experimental onde o soldado dirige um Humvee (veículo militar), baseado no game Full Spectrum Warrior (2004), durante a terapia é adicionada ao game situações desencadeantes de estresse, como tiros e explosões, e o paciente tem seu comportamento monitorado. Em outra situação, games neste estilo são usados para treinar soldados antes de irem para o campo de batalha. No Rio Grande do Sul também foi desenvolvida tal tecnologia para tratamento de Transtorno de Estresse Agudo em vítimas de assalto ${ }^{9}$, vemos com estes exemplos um anel de Moebius entre a tecnologia e a vida.

Baudrillard acha espantoso a tamanha velocidade com que esse anel de Moebius se movimenta, lembremos da Segunda Guerra Mun-

\footnotetext{
Disponível em: http://www.associatedcontent.com/article/317981/lyotard_baudrillard_language_games_pg2. html?cat=38 Acesso em: 15 nov. 2010.

8 Disponível em: http://www.ubishops.ca/baudrillardstudies/ vol4_3/v4-3-article61-mackey.html Acesso em: 15 nov. 2010. 9 Disponível em: http://tecnologia.terra.com.br/mundo-em-3d/noticias/0, OI5033050-EI17669,00-RS+software+D+aj uda+no+tratamento+de+traumas+de+assalto.html Acesso em: 3 abr. 2011.
}

dial, algumas das armas utilizadas possuíam uma baioneta, afim de confrontar o inimigo de uma maneira mais próxima, corpo a corpo, olhando nos olhos do oponente, uma situação da habilidade de luta de um contra a habilidade do outro. Anos depois na Guerra do Golfo, percebemos uma mudança radical no sistema de batalha, onde o apertar de um botão mudaria quase tudo, um conflito quase 'comercial', uma arena humana transmitida ao vivo quase que 24 horas por dia pela TV. Assim no texto "Lyotard, Baudrillard, Language Games and Simulacra, Oh My" (MACKEY, 2007) vemos que:

War in the traditional sense has involved at least two military powers engaged on the battlefield face to face in a death match over territory, economics or ideology. In the Gulf Wars, however, pilots who were responsible for mass death never even came within miles of seeing their victims; those unfortunate people were and are merely inhuman computer images generated within the cockpit of the plane. Baudrillard differs substantially in seeing society as devolving into a series of symbols that is increasingly devoid of tangible connections to reality.

Conflitos hoje em que vidas são apenas um número de série ou um ponto colorido em um visor de cristal líquido, Baudrillard nos fala da perda uma imagem de realidade que tínhamos antes, hoje com uma série de signos voláteis, alfa numéricos ou em alguns casos, binários ou se é 1 ou se é 0 . Uma reconfiguração da realidade alimentada pelo virtual dos games e este ao mesmo tempo como uma dobra, os games alimentados pelo real, como os games de futebol. Quando estes games surgiram eram baseados nos jogos de futebol vistos pela TV, com ângulos de câmera, imagens e jogabilidade ainda precários devido a sua época (final dos anos 80 e inicio dos 90). Mas com o desen- 
volvimento da tecnologia para este propósito, os games de futebol ficaram mais próximos a uma partida 'real' transmitida por emissoras de TV, hoje a ponto de os games serem confundidos com uma partida ao vivo, devido aos ângulos de câmera, imagem e sons excelentes, o que de alguma forma está sendo utilizado por emissoras de TV e implantado em estádios para proporcionar ao torcedor uma experiência diferente (vista apenas em games). Como anos atrás, 'surgiu' a idéia de alguns estádios da Europa possuírem a capacidade de um replay instantâneo no caso de alguma falta cometida pelos jogadores ou em caso de dúvida relacionada à opinião do arbitro. O que foi muito debatido durante a última Copa do Mundo (proibido pela FIFA), uma vez que segundo os árbitros, tal tecnologia poria em xeque a capacidade do profissional em campo, outra opção debatida pela FIFA até novembro de 2010 , foi a implantação experimental de um chip no interior da bola em caso de um 'gol duvidoso'.

Como em Medal of Honor (neste caso baseado na Segunda Guerra Mundial), foram chamados veteranos de guerra para deixar o game mais 'autêntico', tanto em relação ao combates como na própria atmosfera de guerra, sendo reproduzida de maneira 'fiel' ao momento em que os até então soldados enfrentaram, como o desembarque na praia de Omaha. Mesmo sendo para alguns uma cópia fiel ao momento em que gerou terror e pânico para muitos, este mesmo momento está sendo de certa maneira reproduzido para entretenimento e a tecnologia contribui para que as imagens tornem-se mais reais, sons mais penetrantes e sua possível conseqüência, uma sensação de se estar em combate, dirigir veículos um simplesmente olhar para um céu em três dimensões. Isso também está sendo usado nos cinemas, tanto $3 D$ como em $4 D$, este último reproduz mudan- ças climáticas e de temperatura, por exemplo, se chove no filme, então 'chove' no cinema.

Quanto mais virtual, mais real, viver em uma virtualidade de imagens, uma 'reconfiguração da realidade alimentada pelo virtual dos games' como dito mais acima.

Notamos isso a cada semana, se não a cada dia, produtos são vendidos ao montes devido a sua aproximação com um controle ilusório do virtual, conexões sem fio, amigos e mensagens instantâneas, relações começam e terminam em um click.

Quem não pertence a esse grupo inserido na tecnologia está "analogicamente" excluído, como se seu não pertencimento fosse algo ilegal, contra uma moral, contra o consumo, está 'fora' pois deve ser 'incluído", a mídia e o capital disseminaram o discurso moral de que, quem possuir tal e tal aparelho está no caminho certo, ninguém precisa ser um biomecânico ou ter visto inúmeras vezes os filmes Matrix (1999) ou Tron (1982/2010) para perceber que estamos mais frágeis ao mesmo tempo que nos vendem a ilusão de força e quase imortalidade digna de semi deuses. Criadores e destruidores de mundos.

Percebemos até o momento que uma parcela dos games produzidos adentram nosso mundo por vias pedagógicas bem como games elaborados para fins de treinamento e terapêuticos, possibilitando situações simplificadas do cotidiano de seus jogadores para posteriormente defrontarem-se com ocasiões de exigência mais complexa de vida. Neste aspecto o game se apresenta como uma reprodução da realidade, como jogos de Corrida, Futebol ou de Tiro com visual mais próximo daquilo que vemos nos noticiários e em nosso cotidiano, nossa vida sendo reproduzida em um mundo virtual e nos sendo vendida ou talvez "re-vendida", sempre o mesmo através da tran- 
qüilidade da repetição com suas linearidades e limitações de exploração, com dificuldade de abertura para a diferença e possibilidade de repensar nossas práticas de vida (em sua maioria), uma grande barreira para um olhar nômade frente a cristalização de games onde o objetivo é o visual mais próximo do seu conceito de real, como games de Ação. Nesta função o game se apresenta como cópia pragmática de uma realidade como representação simplificada. Temos ainda dentro desta lógica de reprodução do bom-senso e do senso-comum, os games que buscam se aproximar tanto quanto for possível do referente real. Para tanto se utilizam de diversas estratégias que mesclam ambos os mundos. Mas também temos os games que ultrapassam esta lógica e possibilitam a invenção de linhas de fuga para outros mundos possíveis.

\section{Games como criação de outros mundos possíveis: efeitos de fuga e mass effect}

Então nesse espaço, a intervenção crítica dos games nos abre os olhos, mesmo que de uma maneira violenta, não violenta como um martelar de dedos, mas violenta de espantosa, de revelar o que então era apenas uma ilusão criada pelo consumidor, apropriada por um dito saber e vendida ao seu próprio criador, games como Mass Effect (2008) considerado uma "Space Opera10" nos causam esse efeito de abertura, de repensar nós mesmos quanto espécie humana.

Em Mass Effect (2008), você escolhe um personagem (humano) mudando suas carac-

\footnotetext{
${ }^{10}$ Neste caso, um dos conceitos atribuídos a ficção científica, com uma narrativa romântica, personagens que remetem a heróis gregos e cenários no mínimo exóticos além da presença de tecnologia avançada e alienígenas.
}

terísticas conforme seu gosto (por exemplo, caráter agressivo ou não, gênero e atributos físicos), sua missão é encontrar um artefato alienígena milenar em um planeta distante, tal tecnologia pode possibilitar a abertura de formas outras desenvolvimento tecnológico. Em certo momento Shepard (sobrenome de seu personagem) acaba se envolvendo em uma situação em que um integrante (Nihlus) de seu time é morto por um agente renegado (Saren) que a principio imaginou-se sendo um de seus aliados, o que ocasiona um conflito diplomático entre membros de um conselho galáctico com os seres humanos, em especial com seu personagem e este deverá procurar provas para fundamentar os argumentos de que todos foram traídos por Saren, além de procurar tal agente renegado e descobrir seus verdadeiros planos ao longo do game, e descobrir também, que segredos tal artefato milenar guarda a ponto de toda crise se estabelecer devido a sua procura.

No decorrer do game percebemos algo distinto de outro do gênero, os humanos não são o centro do mundo, neste caso do universo, o jogador deve reconhecer que os personagens não giram a sua volta e atuam de maneira independente, e o jogador depende destes para concluir ou não uma missão (com conflito armado ou não). Para termos uma idéia do conteúdo crítico e político (no sentido de coletivo), no game, os humanos desejavam pertencer a um conselho responsável por acontecimentos na galáxia, com uma semelhança a ONU, mas um de seus integrantes alienígenas (lembremos que os humanos também são considerados aliens) argumentou que humanos não conseguem conviver nem com os da sua própria espécie e não poderiam atuar em algo de tamanha responsabilidade, além do fato de que os humanos só dispunham de tecnologia 
avançada devido a uma descoberta arqueológica cujo "efeito em massa" ocasionou um avanço de séculos para a tecnologia e sociedade humana, como por exemplo, os humanos tivessem descoberto algo que possibilitasse ter internet wireless no séc. XVIII.

Uma tentativa de pensamento, Mass Effect (2008) possibilita não mais uma forma de recriar um mundo posto como visto mais acima sobre cópia modelo, mas este game tenta criar um outro mundo possível. Demanda surgida não apenas em um título específico ou um território apenas, como música, cinema ou literatura, percebemos quando desejamos abrir o peito e tirar as armaduras que nos vendem e também ajudamos a construir ao longo de séculos, pôr em xeque certezas dogmáticas que abalam o mundo a nossa volta, não ser o centro do sistema solar, não ter nascido de um ventre divino. Tais questionamentos podem ser experimentados em games, não vistos mais como mera fonte de diversão, mas como uma ponte com as artes, com a literatura, por exemplo, potencializando ainda mais as produções não apenas entre o real e movimentos virtuais, mas sim potencializar a vida quanto rizoma.

Não podemos enfraquecer os efeitos de um game ou um livro como Ulisses de Joyce ou um filme, pois iremos amputar sua própria potência de criação ao mesmo tempo a nossa própria potência de vida, a potência de produzir um efeito e nos afetarmos, movimento este sempre múltiplo e mutável, questionador de práticas, das imposições, aí está o devir arte nos games, uma declaração problematizadora ao absoluto como em Mass Effect (2008), levantando suas velas no mar da internet e em mídias de modo geral, fugidios a ponto de não serem contornados, enclausurados, mas sim desenvolvidos.
Como a literatura, segundo Gilles Deleuze em seu escrito "A Literatura e a Vida", escrever "não é narrar recordações" (1997) ou qualquer outro fato. Ao nos surgir um processo de outramento, começa então a literatura. E os games não estão longe disso, uma produção que vai além das palavras, sem ter necessariamente uma língua hegemônica, atuam como linha de fuga de uma moral ou ordem imposta, viriam a ser uma invenção de outro momento como nos games Fallout 3 (2008) e Mass Effect (2008), experimentação de outros mundos e formas de vida (por vezes utópicos), como Edson de Souza ${ }^{11}$ nos fala:

Quando falamos em utopia estamos pensando tanto nos pequenos movimentos que podem redirecionar uma vida a partir de uma pequena atitude como dentro do espectro dos movimentos sociais. Para que a forma utópica consiga seu lugar é preciso vencer uma inércia inicial, a qual muitas vezes nos imobiliza em um devaneio que não se materializa nas atitudes.

Assim como a literatura ou cinema, sem tender a uma dominação ou criação de verdades, games não são uma forma de impor um olhar supremo referente a algum acontecimento, mesmo aqueles games que nos propiciam recordar algo de outro momento, mas se movimentariam de maneira como Proust e suas madeleines, tratando-se da diferença, algo além de possíveis palavras ${ }^{12}$, games e literatura como um anel de Moebius na/com a sociedade, um processo de eterno devir revelando-se a cada movimento, este segundo Deleuze

\footnotetext{
11 Disponível em: http://www.fundamentalpsychopathology. org/material/pesquisas_em_andamento/sousa_psicanalise. pdf. Acesso em: 28 nov. 2010.

${ }_{12}$ A Microsoft desenvolveu uma tecnologia que permite o usuário não mais usar um controle para seu vídeo game, neste caso, um aparelho fará a leitura corporal do jogador e conforme ele se movimenta, seu personagem também o faz. Quê pode um corpo?
} 
(1997), movimento de invenções, um escrever/jogar sempre em devir, sempre em outramento com as paisagens, com os ventos, com a própria língua, tentar o diferente percebendo as repetições que a literatura e os games nos remetem, batalhar não pelo mesmo mais de dez vezes seguidas, mas batalhar pela diferença, pela invenção de uma possibilidade de vida é o que os gritos de vários autores/produtores nos perfuram os tímpanos, desde que - parafraseando Spinoza, nos deixemos afectar com o bloco de sensações que tais movimentos nos possibilitam.

Para além de uma metafísica ou de um naturalismo, seriam os games uma linha de fuga, uma dobra para escancarar 'um mundo dos sentidos"? Efeitos?

Propor uma fissura de um discurso hegemônico ditador de regras morais barrando qualquer produção artística que se opunha a ordem discursiva vigente, assim marginalizando a produção de games (como foi com o cinema em seu surgimento), pois estes vistos como simulacros diria Deleuze, mutantes, linhas de fuga, inconformados, beirando $o$ infinito, potência para produção duplos. Talvez por tal desenvolvimento tecnológico, chegará um momento que como no filme "A Origem" (2010) os personagens não sabiam se estavam sonhando ou não, no nosso caso, poderemos 'não saber' se estamos atuando em um game ou não.

$\mathrm{Na}$ sociedade há algumas formas de controle, especialidades junto a outro/Outro, que estão possivelmente naturalizadas, sempre visíveis, mas pouco percebidas, interpretativa e conseqüentemente a dar uma explicação com toques de verdade, esta socialmente aceita para o bem estar geral de determinada ordem. Como juízes, médicos, advogados, professores, psicólogos, padres, muitos outros geren- ciadores de sentidos, determinados saberes que podem nos manter presos, na mesma linha na areia, na mesma estação climática, talvez soprando o vento na mesma direção. Não cabe aos games criados reproduzir e dominar com ordens discursivas os corpos já amarrados, açoitados a cada canal de televisão ou a algum outdoor na rua, claro que podem fazê-lo, mas não potencializará em nada a vida, não serão uma criação de novos mundos, um repensar o presente, mas apenas reproduzirá uma dada realidade, possibilitando apenas a tranqüilidade, a tranqüilidade da repetição, "pois as amarras que fornecem segurança, são as mesmas que aprisionam" (KIRST et al., 2003, p. 94).

Quebrar ou provocar uma rachadura no cristal, aquilo que se estabilizou a nossa volta? Perceber o cristal já pode ser alguma coisa. Games pondo em evidência a padronização da vida e o consumo acelerado de objetos fazendo do questionamento da repetição surgir a diferença, uma invenção de conceitos (de games), potencialização da vida e não suspender o desejo pelo novo com uma forma hegemônica discursiva.

Um game pode ser um lugar de perda, ganho, certezas e incertezas, intenções, tensões, unidade e diversidade, sentimentos e razões, de contrários, às vezes quando não se é dito, aparece na sua mais brilhante forma (como o 'extinto' cinema mudo).

Como diz Jean-François Lyotard (1998, p. 101):

De todos os saberes, somente uma ínfima parcela é acompanhada por um reconhecimento oficial de títulos ou diplomas. Mas uma infinidade de conhecimentos, que todos podem possuir em um momento ou em outro, aqui e ali, sua pertinência econômica, lúdica, social, científica etc. circulam clandestina- 
mente, crescem em silêncio, invisíveis, atuantes, prontas para servir.

Os designers de games sabem mais do que ninguém como manter pessoas horas e horas na frente de uma tela jogando sem parar com tamanho investimento de energia para cumprir tarefas, animados, motivados... e a industria de games hoje nos mostra não só empiricamente tamanha força e comprometimento de ambas as partes, mas então, como transmutar essa motivação, dedicação e talvez até uma ética para outros territórios de vida? Transformaria a vida em um jogo em que se faz tudo por "pontos" e ela já não o é?

Mas em um game não desistimos, continuamos, mesmo que ocorram perdas, foram feitos para que não se desista e que sejamos potentes e dignos do que nos acontece como diria Nietzsche, neste caso um olhar nômade a respeito de um game pode proporcionar uma importante ferramenta para nossa vida.

\section{Games como criação de outros mundos possíveis: welcome to the wasteland}

Neste caso, uma parcela desviante, nômade, circula neste exato momento, servindo a possibilidade de propiciar uma possibilidade, propor novos mundos outros, gamers modificam os games para deixá-los diferentes dos originais vindos de "fábrica", como por exemplo, o game Fallout: $3(2008)^{13}$, a empresa

\footnotetext{
${ }^{13}$ Neste RPG de Ação, o jogador explora a cidade de Washington do ano de 2277, quando a terra foi devastada por uma guerra nuclear, o jogador tem de encontrar seu pai, além de ter que sobreviver em um ambiente desértico com fauna e flora transformada pela radiação excessiva, podemos associá-lo a Os filmes como: Mad Max (1979), A Estrada (2009) e O Livro de Eli (2010).
}

produtora do game disponibilizou um programa para que os jogadores ao redor do mundo mudem o que quiserem no game, criando seu $M O D^{14}$, acrescentando novos itens, diálogos, o que quiserem, para assim deixarem o game mais interessante:

As maltas, os bandos são grupos do tipo rizoma, por oposição ao tipo arborescente que se concentra em órgãos de poder. É por isso que os bandos em geral, mesmo de bandidagem, ou de mundanidade, são metamorfoses de uma máquina de guerra, que difere formalmente de qualquer aparelho de Estado, ou equivalente, o qual, ao contrário, estrutura as sociedades centralizadas (DELEUZE, 1997, p. 16).

Os jogadores desenvolvedores, máquinas de guerra (de modificações), almejam um território liso, menos hierarquizado, sem instalação hierarquizada como em uma empresa ou estabelecimento de produção territorializado. Os jogadores utilizam-se de um território estriado como um game "pronto", vendido em massa para jogadores de todo o mundo para que assim com seus mods desenvolvam outros olhares, linhas de fuga a respeito de algo dado como fechado, exteriorizando algo que não foi possível originalmente sem abertura de modificação de um espaço/tempo, quebrando repetições, não "em termos de independência, mas de coexistência e de concorrência, num campo perpétuo de interação, que é preciso pensar a exterioridade e a interioridade" (DELEUZE, 1997, p. 19).

Assim como em alguns casos a apropriação

\footnotetext{
${ }^{14}$ Abreviatura de Modfication designa a alteração feita em certos aspectos do game, música, dificuldade, jogabilidade, novas fases ou personagens etc... Criar outras possibilidades no game feito pelo próprio jogador, em alguns casos disponíveis gratuitamente para download em sites de outros jogadores sem vinculo com a empresa proprietária do game modificado.
} 
de um saber ocorre alguns mods feitos para o game Fallout: 3 tiveram sua inserção na seqüência deste game, Fallout: New Vegas, um mod em que o personagem teria que se alimentar, e curar suas próprias feridas, foi "inserido" em New Vegas, mas de maneira sutil, posto que para alguns era novidade, mas para quem conheceu a modificação que possibilitava o mesmo (e até mais elaborado) em Fallout: 3 foi gritante a captura de um saber menor por um saber dominante, tornando uma produção nômade em sedentária (como em casos de hackers e crackers tendo seus serviços contratados por empresas para que os mesmos elaborem sistemas de segurança mais eficazes), neste caso universalizante, fixando a força de trabalho a fim de "regrar o movimento do fluxo de trabalho, determinar-Ihe canais e condutos, criar corporações no sentido de organismos, e, para o restante, recorrer a uma mão-de-obra forçada, recrutada nos próprios lugares (corvéia) ou entre os indigentes (ateliês de caridade)" (DELEUZE, 1997, p. 28), ao contrário de um devir menor como desenvolver um mod que almeja a potência da singularidade.

Entre os mods feitos para Fallout: 3 (2008) está um muito interessante, esse em particular retira todos os objetivos do game, deixando o jogador explorar a Capital Wasteland livremente, e encontrar objetivos ocasionalmente se desejar.

O "cartógrafo e objeto nascem juntos e percorrem a vida de modo inseparável na criação de problemas" (KIRST, et al., 2003, p. 96), assim a exploração de um mundo criado a cada passo, descobrindo-se em um caminhar rizomático não se atendo a objetivos de olhar linear como proposto no game, mas um jogar sem objetivos, sem pontos de referencia pré estabelecidos, algo possibilitado por outro andarilho (um fazer molecular não mais molar como fora imposto a princípio), outro Wastelander, farto de seguir a linearidade da própria vida representada em um mundo virtual do qual resolveu retirar (ou deixar de lado) todos os objetivos do game, deixando o game um universo onde talvez o único objetivo é não ter objetivo:

A cartografia, assim, pode ser pensada como 'máquina' que tem incorporada a emergência, a finitude, a criação, a produção/destruição. Não está ligada, portanto, à vontade racional fixa, unívoca e representacional, mas ao inconsciente, que se estende por sobre tudo, para além da história que conhecemos em direção às origens do humano. O maquínico cartográfico se caracteriza não por que faz retornar o mundo em forma de ficção, mas por que o mundo recriado adentra o sujeito e pode modificá-lo, sobrevivendo na medida em que opera pontos de vista e "encorpa" subjetividades (KIRST, et al., 2003, p. 99).

No entanto ao longo da caminhada aparecem "afazeres" para completar e aumentar a capacidade do personagem como aumentar sua força ou outra qualidade, mas os objetivos são todos secundários, mesmo os originalmente "principais". Neste caso, depende mais da intenção do jogador aumentar as qualidades do seu personagem ou não.

Ora, se entendemos que os movimentos da subjetividade são nômades e transitórios, em suas vibrações vamos pousar a nossa atenção, para que, desse encontro singular, seja possível a construção de uma nova sistemática de sentido. Em meio a complexidade do pensar, abrimos o sensível e o inteligível ao corpo e as reconfigurações singulares do ser, aos intercessores criados, para estarmos mais atentos aos movimentos do desejo que produz sujeitos e os transformam em novos modos de si (FONSECA, et al., 2010, p. 171). 
Com movimentos paradoxais que põem em evidência padrões morais que fazem parte de nosso cotidiano como, comer carne humana para sobreviver ou ver seu personagem enfraquecer por não comer, uma possibilidade de repensar os diversos saberes e "informações e expressões como inventores da complexa condição humana nos devires da produção de conhecimento" (FONSECA, et al., 2003, p. 101) vemos a potente ferramenta que são os games para a filosofia e para a vida e neste caso, depende do jogador tomar tais tipos de decisão em um universo de possibilidades de expressões de vida.

Talvez entendendo tal movimento como um "corpo sem órgãos" na prática do jogar, um momento anterior a uma posição de identidade que nesse caso irá se des/envolver ao jogar pondo em evidência o social e o seu desejo, bem como utilizar ou criar um mod nos remete a uma devir minoritário da game cultura, não sendo uma caixa de ressonância de uma única história, mas sim com a possibilidade de criar outros mundos (mods) remeteria a uma proliferação de fluxos erráticos como na literatura, pensemos os games/mods em conjunto ao processo de construção literários (mods e seus criadores como um devir-menor), assim segundo Eduardo Pellejero:

Porque se é certo que toda a saída possível passa por romper com a história e os discursos que se reclamam da história, não é menos certo que estas transformações não se fazem no espelho do céu, mas no solo sempre disputado, sempre em jogo, dos territórios estabelecidos e da terra expropriada ou deserta (PELLEJERO, 2008 p. 72).

O jogador nômade movimenta-se em um território liso, intuitivo, com um corpo vibrátil. Jogar com mais possibilidade de decisões e ao mesmo tempo sem um planejamento prévio de cada ação (um jogar/viver errante e abarrotado de dúvidas), como nadar em um rio de fluxo intenso como a vida, mas não podendo "parar" para se pensar para que lado ir, pois o fluxo da vida não pode parar e o nadador deve tomar suas decisões no movimento incessante, o tempo não pára e esse jogar propiciado pela retirada de objetivos possibilita este território 'inexato" posto que pela percepção de cada passo e decisão feita, motiva o jogador a repensar sua própria prática tanto no game como na sua vida e perceber que no game ele pode muito bem "salvar" em partes que acha importante, neste caso podemos entender "salvar" no game como um recorte da própria história criada, da própria vida em evidência e sua possível importância na tomada ou não de decisões. Ele, o jogador, o personagem, o wastelander (itinerante, ambulante), esta terceira pessoa potente desprendendo-se de amarrações ou hierarquizações lançadas por enunciações de saber legitimadores jogadores de xadrez (institucionalizado, com linha de frente e retaguarda, movimentos em espaço fechado e delimitado, território estriado), o go, ao contrário, este sem linha de frente movimentos em espaço aberto, território liso o devir-gamer como uma máquina de guerra nômade, seja em um deserto como Mojave seja em um deserto de gelo como a Sibéria:

Os peões do go, ao contrário, são grãos, pastilhas, simples unidades aritméticas, cuja única função é anônima, coletiva ou de terceira pessoa: "Ele" avança, pode ser um homem, uma mulher, uma pulga ou um elefante. Os peões do go são os elementos de um agenciamento maquínico não subjetivado, sem propriedades intrínsecas, porém apenas de situação (DELEUZE, 1997, p. 8). 
Fallout: 3 (2008) remete-nos à uma cartografia de um mundo destruído, detentor de novas formas e práticas de vida, de possibilidades de experimentação, a capital Washington destroçada, fúnebre, amedrontadora em seu deserto de um mundo radioativo onde vida/ morte partilham o mesmo território. $O$ jogador pode seguir um caminho nômade nesta Wasteland afetando-se a cada encontro, tornando se um "wastelander", um cartógrafo:

Cartografar remonta a uma tempestade... Tempestade de escolher rotas a ser criado, constituir uma geografia de endereços, de registros de navegação, buscar passagens... Dentro do oceano da produção de conhecimento, cartografar é desenhar, tramar movimentações em acoplamentos entre mar e navegador, compondo multiplicidades e diferenciações. Ao mesmo tempo, sustentar uma postura ético-estética de acolher a vida em seus movimentos de expansão segundo implicações políticas do tempo, do perspectivismo, da contingência e invenção (KIRST, et al., 2003, p. 91).

Vemos algo assim, próximo, fugidio, a intrincada velocidade de relações a cada esbarro por ruas e vielas de uma cidade, bairro ou corredor de bar, James Joyce em seu livro Dublinenses (2003) nos mostra relâmpagos intensos das relações interpessoais, desejos e frustrações. Relembrar, jogar novamente, mas sentindo algo de diferente posto que fora outra época, outro momento, outro ser, sempre outro ser, frutos de agenciamentos, estes segundo Deleuze (1997) são sempre passionais, compondo desejos, este ultimo sempre existirá agenciando/agenciado/maquinado. Os olhos gastos, mas gastos pelas impressões milimétricas do mundo fora/dentro parecendo o mesmo a olhos 'novos', mas a cada piscada, os globos são lubrificados com mundos outros, coloridos, fúnebres, intensos (tensos), com intenções possibilitadoras de fuga da repetição, de um sofrer ou de certa forma ir direto ao terror, agonia e pânico de sentir que a vida não é controlada, nos escapa ao mesmo tempo em que criamos um saber que diz que a temos em nossas mãos, várias vidas, várias possibilidades para o novo, "ao mesmo tempo, sustentar uma postura ético-estética de acolher a vida em seus movimentos de expansão segundo implicações políticas do tempo, do perspectivismo, da contingência e invenção (KIRST et al., 2003, p. 91)" como dito mais acima. E que: "a voz de tom forte e claro, interpretou com grande talento os trinados que enfeitavam a melodia e, embora cantasse muito rápido, ela não perdia uma única variação tonal. Acompanhar a voz, sem olhar para a cantora, era deixar-se levar vôo leve e seguro" (JOYCE, 2003 p. 192). A voz que os games tem, muitas vezes são entendidas ou ouvidas (não escutadas) como o som agudo de uma caixa registradora que sucedem uma venda, isso, pois muitos vêem os games como mercadoria, fazer-los e vende-los, lucrar o máximo possível, usá-lo como um corpo (Foucault, 2001), uma "biopolitica" do game, extrair o seu máximo possível, esquadrinhá-los com gêneros e subgêneros para melhor administrá-los e assim manter os ganhos monetários sempre ao máximo que for possível:

O homem moderno evita o sensível, pois este é fugidio, e o seu corpo, como se prisão fosse, pois o submete ao duplamente incontrolável: o sensível das sensações e o irascível das paixões. Entretanto, sob jugo da Razão, ouve-se um grito de liberdade de individuo e seus ímpetos, paixões e peculiaridades. Pois, as amarras que fornecem segurança, são as mesmas que aprisionam. Nietzsche irá dizer que a aparente ausência de cores da assepsia do método, nada mais é do que uma pin- 
tura que busca expressar com suas tintas a ausência de coloração. Ao invés de construir uma posição externa às outras, desde onde tudo se pode ver isto não passa de mais uma perspectiva, afirmada por uma "vontade de não ter vontade (KIRST, et al., 2003, p. 94).

Certo número de games tentou escapar dessas amarras, tornando-se assim mutáveis com velocidade cada vez maior ajudados por jogadores e suas armas de resistência como os mods, como um movimento em ritornelo aumentado a potência de afetação do game para com o jogador e vice versa. O jogador/ leitor move-se em outramento como no livro de James Joyce, Dublinenses (2003) e neste caso principalmente no game Fallout 3 (2008), torna-se estrangeiro de si mesmo, experimentando novos modos e espaços de existencia e devires de mundo. Tornar o game em questão violento ou pacífico, ativo ou passivo, liso ou estriado, depende do jogador ao jogá-lo:

[...] as figuras só são consideradas em função das afecções que Ihes acontecem, secções, ablações, adjunções, projeções. Não se vai de um gênero a suas espécies por diferenças específicas, nem de uma essência estável às propriedades que dela decorrem por dedução, mas de um problema aos acidentes que o condicionam e o resolvem. Há aí toda sorte de deformações, transmutações, passagens ao limite, operações onde cada figura designa um "acontecimento" muito mais que uma essência [...] (DELEUZE, 1997, p. 20).

Tanto Fallout: 3 como seus mods escancaram o afecto de seus jogadores/criadores, estes vendo a cada passo as conseqüências de suas ações e perceber no decorrer do jogar que o mundo também se afeta com sua presença (e vice versa), "amor ou ódio já não são em absoluto sentimentos, mas afectos" (DELEUZE, 1997, p. 13), neste caso, o jogador que optar tornar cada ato violento, a escolha de "atirar antes e perguntar depois" causa um turbilhão no game e como os personagens próximos reagirão com tal ato, bem como o jogador que escolher perguntar antes e não atirar. O jogador exteriorizará cada sonho, desejo que almejar produzir no game.

Percebemos que com os games somos: convocados a construir novas tramas e a mapear as crises que geram uma estranha permanência daquilo que passa e sofre alterações diversas, a tecermos uma densa geografia dos afetos, como uma cartografia das dobras entre o sensível e o inteligível, plano múltiplo que reconecta a heterogeneidade das forças e formas (FONSECA, et al., 2010, p. 170).

Assim podemos exercitar nossos olhares para perceber os games não mais com desdém ou objetos de ganho monetário, mas sim, como uma potente ferramenta para o entendimento de novos olhares de imanência, "como apostar em uma Psicologia que se torna sensível aos acontecimentos e aos encontros com um plano caótico e vivo, produtor de crises e novos enredos para o sujeito e a vida?" (FONSECA, et al., 2010, p. 171).

\section{Os games poderão ser vistos como um ato de resistência? Ao quê?}

O artista ou o filósofo são de todo incapazes de criar um povo, apenas podem chamá-lo com todas as suas forças. Um povo só pode ser criado com sofrimentos abomináveis, e já não pode ocupar-se mais da arte ou da filosofia. Mas os livros de filosofia e as obras de arte também contém a sua soma inimaginável de sofrimento que faz pressentir o advento de um povo. Têm em comum a resistência, a resistência à morte, à servidão, ao intolerável, à vergonha, ao presente (PELLEJERO, 2008 p. 76). 
Em uma palestra realizada em 1987, Gilles Deleuze nos diz que "o ato de resistência possui duas faces. Ele é humano e é também um ato de arte" e complementa, "somente o ato de resistência resiste à morte, seja sob a forma de uma obra de arte, seja sob a forma de uma luta entre os homens".

Por vezes a cinegrafia seguiu (e segue), a ordem discursiva para efetuar sua produção e conseqüentemente existência (ser lembrada por anos), uma lição de moral no final de filmes, ou aqueles exemplos 'moralmente justos' em que o bandido é sempre morto pelo mocinho. Além do clássico final hollywoodiano, todos ficam felizes para sempre. Agora filmes são baseados em games, e estes, nem sempre possuem finais felizes. Filmes tornam-se games. Livros conseqüentemente foram 'adaptados' para essa outra forma de produção, contos de H. P. Lovercraft viraram games, além de muitos outros. Retomemos Deleuze (2006), este autor nos diz que os intercessores - plural mesmo são indispensáveis para promover encontros assim possibilitar ao pensamento uma saída à sua imobilidade natural, sem intercessores não poderá ocorrer criação, e pensamentos, ele nos diz:

A criação são os intercessores. Sem eles não há obra. Podem ser pessoas - para um filósofo, artistas ou cientistas; para um cientista, filósofos ou artistas - mas também coisas, plantas, até animais, como em Castañeda. Fictícios ou reais, animados ou inanimados, é preciso fabricar seus intercessores. É uma série, mesmo que completamente imaginária, estamos perdidos. Eu preciso de meus intercessores para me exprimir, e eles jamais se exprimiriam sem mim: sempre se trabalha em vários, mesmo quando não se vê, e mais ainda quando é visível [...] (DELEUZE, 2006, p. 156).
Vemos os games e sua potência intercessora como a literatura, games como uma máquina de expressão e de produção de novos campos de possíveis posto que coletivos, assim como a literatura, além de mera diversão, atuam a sua maneira distinta escancarando as impossibilidades de cada dia, atuantes contra um lógica de pensamento maniqueísta e banalizador da vida, resistentes a repetição de cada momento histórico, rascunhando um mapa de situações pela efetividade de expressões tantos dos escritores/jogadores/produtores, enfim, criadores observadores de cada momento onde se está inserido como sujeito histórico, que afeta e é afetado.

\section{Game over ou vidas infinitas?}

Filmes, livros e games intercessores uns dos outros, possibilitando novos olhares para se pensar a vida. Pensemos os games como intercessores potentes para a Psicologia e esta dos games para que a Psicologia não venha a:

[...] se fechar a essas vibrações, pois, nesse caso, ela correria o risco de se tornar mera reprodução de verdades já reveladas. Perguntamos, pois, como abrirmos o campo psi para novas emblemáticas e perfurações de seus fazeres e dizeres? Como apostar em uma Psicologia que se torna sensível aos acontecimentos e aos encontros com um plano caótico e vivo, produtor de crises e novos enredos para o sujeito e a vida? [...] (FONSECA, et al., 2010, p. 171).

Em Fallout 3 (2008) não vemos mais a mera dualidade cópia/modelo, estamos sim falando de outro mundo além de um foco especifico onde a preocupação é "o que se parece com o que?" (realismo gráfico/físico), mas sim vivenciar outras formas de vida, nunca comparando 
e sim, associando cada momento, cada encontro no game, deixando o jogador se permitir a afetar e ser afetado com sua própria força em um jogar rizomático, um devir-gamer onde pode-se criar um mundo onde a única impossibilidade é imposta pelo jogador/sujeito, este pondo em evidência suas próprias limitações como sujeito de enunciações e atravessamentos discursivos da cultura e sociedade onde vive. Como no filme Tron (1982/2010), temos que 'entrar' neste universo virtual para melhor cartografá-lo, uma cartografia do game Fallout 3 (2008), nunca neutro, pois se está lá e aqui, sentindo cada sopro, cada decisão, tencionando o jogador a perguntar-se "o que posso fazer?".

Os games quanto um ambiente híbrido dando abertura a uma nova discussão sobre a própria vida que levamos no contemporâneo, pois podem ser intercessores construídos a partir de um olhar menor, reconstruídos e que da mesma forma constroem mundos culturais na sociedade atravessando instituições modernas como família, escolas e até hospitais, isso impulsiona um pensar sobre estes acontecimentos cada vez mais intensos e convida a Psicologia a perceber tais tecnologias do contemporâneo, aponto desta e os games entrarem em 'núpcias' de movimentos que se constroem nômades e singulares, sem nunca congelá-lo e dominá-lo com um discurso de verdade.

Além disso, ao ampliarmos o olhar sobre os movimentos da subjetivação, também nos lançamos ao desafio de alterar as nossas formas de intervir, uma vez que o tecnicismo em Psicologia não dá conta das novas redes ação e existência que cercam os movimentos contemporâneos (FONSECA, et al., 2010, p. 172).
Games percebidos como arte, posto que causam acontecimentos, afetações, agitam molaridades e molecularidades, causam agenciamentos e dimensões múltiplas, além de conceitos de arte já vistos até hoje, pois são diferentes e causam outras percepções, causam singularidades e afetam outras singularidades e paradoxais. Os games pulsam, escapam (não fogem, posto que fugir remete a medo) das normas impostas e por vezes foram criados para contradizer o imposto, abalar estruturas, colocar uma mão gelada nas costas mornas da repetição e comodismo tirando sua sobriedade e agindo como o conteúdo de um sonho contaminante, um delírio de outro mundo possível e um olhar 'aloucado' a respeito de uma vida ilusória e simplista.

Assim, não se trata da especulação de um mundo interno que sobe a superfície, tampouco buscamos o descobrimento de uma verdade em essência. Ao cartografar, tentamos produzir os deslizes do eu, bem como o desmanche daquilo que já fazia sentido, para que, dessa falha, seja possível convocar a perfuração de mundos e o seu próprio estremecimento. Nesse aspecto, cartografamos as desmesuras da paisagem e escrevemos aquilo que transborda o sentir e o pensar, tal qual um devaneio que encontra uma casa e se transforma em abstração colocada em sonho (FONSECA, et al., 2010, p. 179).

A Psicologia pode sim compor fissuras causadas pelas flechas dos games entre o a terra calma quase congelada da vida contemporânea capturada pelo capital e suas repetições com o mar agitado dos games (de invenções, mistura de pensar e sentir, tramas criadas de múltiplos modos, possibilitando encontros potentes de narrativa e poética), mas desértico ainda muito desconhecido e pouco mapeado, possibilitando que as perguntas "jogadas" con- 
taminem ou respinguem nesta terra, tais perguntas percebemos que resistem, tocam as margens duras e barrentas, mesmo com um quebra mar forjado a fogo, o mar continua a bater em sua costa audaz e desatinado, alavancando a mais elevada potência de criação, supondo uma ético-estética da existência de fluxos nômades.

Desse modo, viver no limite entre estas tecnologias virtuais e o real compondo, partilhando sensações e delírios, desenvolver as potencialidades desse anel de Moebius onde a vida pulsa de maneiras tão distintas e onde a criação, a invenção e os devaneios possam existir como ferramentas também para possibilitar novos olhares e entendimentos sobre esta tecnologia dita como moda passageira na década de oitenta, mas presente a cada segundo hoje. A poiética dos games por vezes incomensurável atravessando os sistemas de limitações impostas por leis ou discursos morais, atentando novas percepções e pegam o corpo de surpresa, como se estivesse dormindo e acordasse de salto devido a um susto, vemos isso com o vídeo game Nintendo Wii e o sistema Kinect, onde o jogar não é mais o mesmo, ficar sentado e mexer apenas os dedos, nesses dois casos o corpo físico toma uma atitude contrária, ele todo vibra "o paradoxo corre nos dois sentidos, ao mesmo tempo, entre o tempo de cronos, cronologia linear das coisas, e o tempo de Aion, Acontecimento das virtualidades em composição" (FONSECA, et al., 2010, p.181). Vídeo games e games provocando a crítica das ações e um avesso intenso do passado tanto na questão física do jogar como também ao conteúdo dos próprios games e da sociedade.

Assim, com as presentes problematizações neste texto, tentemos ao menos perceber estas minúcias tão amplas que presenciamos em nosso cotidiano por vezes robótico de sentidos, tentar mirar os games, suas imagens, seus sons não mais como um bem capital, mas uma produção potente de invenções, cultural e social, promovendo sensações e paradoxos onde um mundo outro é possibilitado e que faz questionar nossas próprias práticas, seguindo seus turbilhões de imagens e sensações, seus agenciamentos de territórios gritando pela diferença de olhares. Muito tempo se passou desde consoles feitos de madeira, percebemos hoje as variações virais destes magníficos territórios esperando para serem cartografados, simulacros de vidas infinitas em que rizomas se fazem, sem nunca almejar um game over, posto que não existe fim. Um devir-gamer, imanente, nômade, menor, jogador e compositor de mundos, ele, um desbravador errante de mundos outros de vida.

\section{Referências}

DELEUZE, GILLES. Foucault. 1. ed. 5. reimp. São Paulo: Editora Brasiliense S.A., 2005. Crítica e Clínica. São Paulo: Ed 34, 1997.

DELEUZE, G.; GUATTARI, F. Mil platôs: capitalismo e esquizofrenia. V. 5. São Paulo: Ed 34, 1997.

FONSECA, T. G.; KIRST, Patrícia G. (Org.) Cartografias e devires: a construção do presente. Porto Alegre: Editora da Universidade, 2003. 
.; COSTA, L. A.; MOEHLECKE, V.; NEVES, J.M.; O delírio como método: a poética desmedida das singularidades. Estudo e Pesquisa em Psicologia. UERJ, RJ. Ano 10, n. 1. p. 169-189 Disponível em: > http://www.revispsi.uerj.br/v10n1/artigos/pdf/v10n1a12.pdf <. Acesso em: 20 maio 2011.

JOYCE, James. Dublinenses. Porto Alegre, RS; RBS, 2004.

KASTRUP, Virginia. O Funcionamento da Atenção Flutuante no Trabalho do Cartógrafo. Revista Psicologia e Sociedade. Porto Alegre, v. 19, n. 1, 2007.

LYOTARD, Jean-François. A condição pós-moderna. 5. ed. Rio de Janeiro: José Olympio, 1998.

MACKEY, Robert. Special Issue: Remembering Baudrillard The Iraq War Is Virtually Taking Place. Disponível em: http://www.ubishops.ca/baudrillardstudies/vol4_3/v4-3-article61-mackey.html. Acesso em: 15 nov. 2010.

SEXTON, Timothy. Lyotard, Baudrillard, Language Games and Simulacra, Oh My! Disponível em: http://www.associatedcontent.com/article/317981/lyotard_baudrillard_language_games_pg2. html?cat=38. Acesso em: 15 nov. 2010.

SMITH, Jonas Heide. Book Review: Persuasive Games - The Expressive Power of Videogames. Disponível em: http://game-research.com/index.php/book-reviews/book-review-persuasive-games-the-expressive-power-of-videogames/. Acesso em: 10 mar. 2011.

SOUZA, Edson L. A. de. Utopia, Arte e Psicanálise: aparelhos óticos do contemporâneo. Disponível em: http://www.fundamentalpsychopathology.org/material/pesquisas_em_andamento/sousa_psicanalise. pdf . Acesso em: 28 nov. 2010.

Submetido para avaliação em 24 de junho de 2011.

Aprovado para publicação em 04 de maio de 2012.

\section{Davi Severo Menezes Damian}

Psicólogo, Pós Graduado em Psicologia Social e Análise Institucional. FADERGS - Faculdade de Desenvolvimento do Rio Grande do Sul - Laureate International Universities, Porto Alegre - RS, Brasil. E-mail: davi.damian@hotmail. com 